\title{
Elites empresariais, a questão social e a responsabilidade social empresarial no Brasil e na Argentina
}

Business elites, the social issue and corporate social responsibility in Brazil and Argentina

Élites empresarias, la cuestión social y la responsabilidad social corporativa en Brasil y Argentina

\section{Luciana Oliveira}

- Doutora em Ciências Humanas - Sociologia e Política pela Universidade Federal de Minas Gerais (UFMG)

- Mestre em Sociologia da Cultura pela UFMG

- Graduada em Publicidade e Propaganda pela Pontifícia Universidade Católica de Minas Gerais (PUC-Minas)

- Professora adjunta do Departamento de Comunicação Social e do Programa de Pós-Graduação em Comunicação Social da UFMG

- Pesquisadora associada do grupo de pesquisas Imagem e Sociabilidade (Gris) da UFMG

- E-mail: lucyoli@hotmail.com

\section{Otávio Dulci}

- Doutor em Ciência Política pelo Instituto Universitário de Pesquisas do Rio de Janeiro (luperj)

- Mestre em Ciência Política pela Universidade Federal de Minas Gerais (UFMG)

- Graduado em Ciências Sociais pela UFMG

- Professor da Pontifícia Universidade Católica de Minas Gerais (PUC-Minas)

- Desenvolve pesquisas sobre modelos de desenvolvimento e políticas sociais

- E-mail: osdulci@gmail.com 


\section{Resumo}

Neste artigo procura-se compreender por que, no Brasil, os empresários assumiram a divulgação de discursos e práticas de responsabilidade social empresarial (RSE), quando na Argentina foi a sociedade civil organizada que o fez. Desse modo, além do esforço comparativo - sempre útil para apontar semelhanças e diferenças, criar escalas e perceber generalidades - compreende-se que na abordagem do tema há uma lacuna a ser suprimida: a construção de um marco histórico sobre a ação empresarial em relação à questão social. Como corolário, pretende-se entender o quadro contextual que reveste de sentidos a expressão RSE em cada realidade nacional analisada, levando em consideração o fato de que, mesmo sendo um discurso global, ele não é homogêneo.

PALAVRAS-CHAVE: RESPONSABILIDADE SOCIAL EMPRESARIAL • QUESTÃO SOCIAL • HISTÓRIA COMPARADA • BRASIL • ARGENTINA

\section{Abstract}

In this article one attempts to understand why it was the business people who assumed the dissemination of discourses and practices of corporate social responsibilty (CSR) in Brazil, while it was the civil society that accomplished this in Argentina. Thus, besides the comparative effort always useful in pointing out similarities, differences, creating scales and perceiving generalities -, one understands that there is a gap in addressing the issue that needs to be deleted: the construction of a historical milestone for the business action in relation to the social issue. As a corollary, one intends to understand the contextual framework of meaning that encompasses the term CSR in each national situation analyzed, by taking into account the fact that albeit being a global discourse it is not homogeneous.

\section{KEYWORDS: CORPORATE SOCIAL RESPONSIBILITY • SOCIAL ISSUE • COMPARATIVE HISTORY • BRAZIL • ARGENTINA}

\section{Resumen}

En este artículo se trata de comprender por qué, en el Brasil, los empresarios asumieron la difusión de discursos y prácticas de responsabilidad social empresarial (RSE), mientras que en la Argentina fue la sociedad civil organizada la que realizó esa divulgación. De esa manera, además del esfuerzo comparativo - siempre útil para señalar las semejanzas y diferencias, crear escalas y darse cuenta de las generalidades -, se entiende que en el abordaje del tema existe una brecha a ser superada: la construcción de un hito histórico sobre la acción empresarial en relación la cuestión social. Como corolario, tenemos la intención de comprender el marco contextual que reviste de sentidos la expresión RSE en cada realidad nacional analizada llevando en cuenta el hecho de que, aunque se trate de un discurso global, el mismo no es homogéneo.

PALABRAS CLAVES: RESPONSABILIDAD SOCIAL EMPRESARIAL • CUESTIÓN SOCIAL • HISTORIA COMPARADA • BRASIL • ARGENTINA 
D esponsabilidade social empresarial (RSE) é atualmente uma noção de uso corrente em todo - 1 o mundo. Empresas dos mais diversos segmentos da economia a utilizam como forma de divulgar sua "boa" conduta e expressar uma imagem associada à preocupação com as coisas públicas, não apenas com o lucro privado. Além disso, o tema tem sido amplamente debatido nas esferas estatal, privada e da sociedade civil organizada, bem como no âmbito das agências internacionais, sem falar na comunidade acadêmica. De maneira geral, o movimento em torno da responsabilidade social empresarial traduz certa mobilização, apoiada por entidades, sindicatos e associações (empresariais ou não), a respeito da necessidade de atuação das empresas no âmbito de investimentos tipicamente estatais ou de interesse público - como educação, saúde, alimentação, cultura, meio ambiente. Essa mobilização se fundamenta na visão de que gerar lucro não é o objetivo único das empresas: elas devem ser também capazes de gerar valor social e ambiental. Nisso consiste sua responsabilidade social.

Com efeito, a rápida massificação do tema tem mais obscurecido do que esclarecido a sua leitura como fenômeno social. Incrustado na fronteira entre público e privado, talvez mesmo como importante contributo ao seu delineamento nos últimos vinte anos, muito se fala da RSE como fenômeno gerencial. Sua compreensão, ainda restrita aos estudos de caso e, muitas vezes, presa à descrição e à fala dos próprios atores envolvidos, necessita, em nossa avaliação, tanto de maior vigor teórico quanto de perspectiva histórica para aprofundar certas análises em circulação. Em relação aos casos nacionais investigados em nossa pesquisa defende-se, com base na análise de Felipe Agüero (2002), que o movimento de difusão do tema na Argentina representa um modelo citzen driven, já que sua liderança está na sociedade civil organizada, em contraponto ao caso do Brasil, que é do tipo business driven, liderado pelos próprios empresários. Por que isso ocorre? Este ponto é de fundamental importância, pois oportuniza verificar como os sentidos dos termos da agenda de negócios global se ressignificam nos contextos nacionais brasileiro e argentino de acordo com certa tradição histórica que ordena as relações entre estado, mercado e sociedade.

Os estudos sobre empresários no Brasil podem ser divididos em duas grandes vertentes (DULCl, 1999, p. 150-152). A primeira, de sabor mais clássico, situada na década de 1950 e primeira metade da década de 1960, coloca os empresários em inquestionável posição de hegemonia na condução da modernização do país, fundamentada em duas antinomias que se cruzam (setores modernizantes versus setores tradicionais e nação versus imperialismo). A segunda, que ganha força após 1964, defende que o estado é que tem hegemonia na modernização, embora não se negue com isso a importância do empresariado como ator político por sua presença na esfera decisória governamental, sua capacidade de organização, seus valores e suas formas de atuação.

De uma maneira geral, nos ateremos aos autores da segunda linha interpretativa, na qual se encontra a discussão basilar sobre empresários no campo das ciências sociais hoje. Esses autores propõem, contra a razão dualista que separa e opõe os papéis do estado e da sociedade 
civil no processo de mudança, conforme a vertente clássica, uma abordagem integrada das relações entre ambos, enfocando a atuação da burguesia industrial como um ator oriundo da sociedade civil, considerado como sendo de suma importância nas sociedades capitalistas. A análise sociológica calcada no dualismo tendeu a privilegiar a esfera política ou do estado forte e autônomo como foro privilegiado da mudança, em detrimento de uma sociedade civil supostamente frágil ou fraca como ator político.

Os autores da segunda vertente não negam o papel preponderante que o estado assume nos países ditos de "desenvolvimento tardio", mas procuram não comprometer com tal constatação o peso das ações relativamente autônomas de certos grupos sociais, como o dos empresários industriais. Em torno dessa segunda linha interpretativa, notamos uma unanimidade no que se refere ao sentido da mudança promovida pelo empresariado como parte de um processo histórico no qual se veem elementos de modernidade hibridizados a elementos tradicionais resultando em novos cenários político-sociais ${ }^{1}$.

\section{BREVE RETRATO DO CAMPO DA RSE NO BRASIL E NA ARGENTINA}

Começamos a análise do campo da RSE nos dois países pela apresentação das principais entidades que atuam no setor. Dentre as entidades observadas, o quadro 1 identifica e sintetiza quais são as mais importantes "vozes" promotoras do tema da RSE no Brasil e na Argentina, elaborado com base em pesquisa de campo realizada nas duas realidades nacionais escolhidas para a comparação². O quadro busca apresentar as instituições já alinhadas segundo um critério de correspondência, o que não significa que as instituições tenham o mesmo grau de relevância relativo em cada realidade nacional.

Quadro 1 - Entidades promotoras da RSE no Brasil e na Argentina

\begin{tabular}{|l|l|l|}
\hline \multicolumn{2}{|c|}{ ENTIDADES DE ORIGEM EMPRESARIAL } \\
\hline Brasil & \multicolumn{1}{|c|}{ Argentina } & \multicolumn{1}{c|}{$\begin{array}{c}\text { Critério(s) de } \\
\text { correspondência }\end{array}$} \\
\hline Ethos & Valos/Fundación Tucumán & $\begin{array}{l}\text { São entidades organizadas por } \\
\text { empresários e compostas por } \\
\text { empresas associadas que esta- } \\
\text { belecem a relação entre os de- } \\
\text { safios da empresa e os proble- } \\
\text { mas da nação (embora a Valos } \\
\text { e a Fundación Tucumán tenham } \\
\text { abrangência regional - respecti- } \\
\text { vamente províncias de Mendoza } \\
\text { e de Tucumán). }\end{array}$ \\
\hline
\end{tabular}

\footnotetext{
${ }^{1}$ O mesmo tipo de raciocínio é desenvolvido por Roy Hora (2002) para o caso argentino.

${ }^{2}$ A pesquisa incluiu a formação de um banco de dados com matérias e artigos assinados coletados em jornais (Folha de S.Paulo - 1994-2008 e O Globo - 2003-2008 no Brasil; La Nación -1998-2008 e Clarín - 1995-2008 na Argentina), participação em eventos das entidades promotoras da RSE no Brasil e na Argentina e entrevistas em profundidade com informantes privilegiados. No caso argentino, levou-se ainda em consideração para a elaboração do quadro o Mapeo de promotores de responsabilidad empresaria en Argentina (www.mapeo-rse.info).
} 


\begin{tabular}{|c|c|c|}
\hline $\begin{array}{l}\text { CEBDS (Conselho Empresa- } \\
\text { rial Brasileiro para o Desen- } \\
\text { volvimen-to Sustentável) }\end{array}$ & $\begin{array}{l}\text { Ceads (Consejo Empresa- } \\
\text { rio Argentino para el Desar- } \\
\text { rollo Sostenible) }\end{array}$ & $\begin{array}{l}\text { São escritórios regionais do WB- } \\
\text { CSD (World Business Council for } \\
\text { Sustainable Development) que } \\
\text { trabalham fundamentalmente } \\
\text { com o tema do desenvolvimento } \\
\text { sustentável mas também difun- } \\
\text { dem uma cultura de negócios } \\
\text { baseada na responsabilidade } \\
\text { corporativa. }\end{array}$ \\
\hline $\begin{array}{l}\text { Amcham São Paulo (Câmara } \\
\text { Americana de Comércio de } \\
\text { São Paulo) }\end{array}$ & $\begin{array}{l}\text { Amcham Argentina (Cáma- } \\
\text { ra de Comercio Americana } \\
\text { de Argentina) }\end{array}$ & $\begin{array}{l}\text { São entidades precursoras da } \\
\text { divulgação do tema, sendo sua } \\
\text { principal contribuição a realiza- } \\
\text { ção de uma premiação a empre- } \\
\text { sas e empresários que tiveram } \\
\text { projetos destacados no campo } \\
\text { da RSE. Trabalham com o con- } \\
\text { ceito de cidadania empresarial. }\end{array}$ \\
\hline $\begin{array}{l}\text { Gife (Grupo de Institutos, Fun- } \\
\text { dações e Empresa) }\end{array}$ & $\begin{array}{l}\text { GDFE (Grupo de Funda- } \\
\text { ciones y Empresas) }\end{array}$ & $\begin{array}{l}\text { São entidades que reúnem } \\
\text { fundações de empresas e tra- } \\
\text { balham com o conceito de in- } \\
\text { vestimento social privado com } \\
\text { o objetivo de profissionalizar as } \\
\text { ações filantrópicas por elas reali- } \\
\text { zadas. }\end{array}$ \\
\hline $\begin{array}{l}\text { ADCE (Associação dos Diri- } \\
\text { gentes Cristãos de Empresas) }\end{array}$ & $\begin{array}{l}\text { ACDE (Asociación Cristia- } \\
\text { na de Dirigentes Empresa- } \\
\text { riales - Argentina) }\end{array}$ & $\begin{array}{l}\text { São entidades que reúnem em- } \\
\text { presários cristãos (católicos) } \\
\text { e que trabalham o conceito de } \\
\text { RSE como relacionamento de } \\
\text { valor com as partes interessa- } \\
\text { das. Valor no sentido moral cris- } \\
\text { tão inspirado na doutrina social } \\
\text { da lgreja. }\end{array}$ \\
\hline $\begin{array}{l}\text { Fiesp Federação das Indús- } \\
\text { trias do Estado de São Paulo }\end{array}$ & $\begin{array}{l}\text { Cac (Cámara Argentina de } \\
\text { Comercio) }\end{array}$ & $\begin{array}{l}\text { São entidades de representação } \\
\text { de interesses empresariais (in- } \\
\text { dustriais e comerciais respecti- } \\
\text { vamente) que vêm se dedicando } \\
\text { paralelamente à divulgação da } \\
\text { RSE (embora em proporções } \\
\text { bastante diferentes). }\end{array}$ \\
\hline \begin{tabular}{|l}
-- \\
\end{tabular} & $\begin{array}{l}\text { Aacrea (Asociación Argen- } \\
\text { tina de Consorcios Regio- } \\
\text { nales de Experimentación } \\
\text { Agrícola) }\end{array}$ & $\begin{array}{l}\text { É uma entidade de representa- } \\
\text { ção dos interesses empresariais } \\
\text { rurais que tem buscado discutir a } \\
\text { questão da RSE, sobretudo em } \\
\text { relação à questão ambiental, nos } \\
\text { seus congressos anuais. }\end{array}$ \\
\hline
\end{tabular}




\begin{tabular}{|c|c|c|}
\hline \multicolumn{3}{|c|}{ ENTIDADES DA SOCIEDADE CIVIL ORGANIZADA } \\
\hline Brasil & Argentina & $\begin{array}{c}\text { Critério(s) de } \\
\text { correspondência }\end{array}$ \\
\hline $\begin{array}{l}\text { Ibase (Instituto Brasileiro de } \\
\text { Análises Sociais) }\end{array}$ & El Otro & $\begin{array}{l}\text { Entidades da sociedade civil que } \\
\text { têm, dentro de um espectro mais } \\
\text { amplo de atividades, um grupo } \\
\text { de trabalho em RSE. Ambas } \\
\text { são afiliadas da Red Puentes. } \\
\text { El Otro tem certa afinidade com } \\
\text { o GAO (Grupo de Articulação } \\
\text { das ONGs Brasileiras) na ISO } \\
\text { 26.000, já que é a representan- } \\
\text { te da sociedade civil no Comité } \\
\text { Espejo Argentino. }\end{array}$ \\
\hline Transparência Brasil & Poder Ciudadano & $\begin{array}{l}\text { Entidades da sociedade civil (no } \\
\text { caso da primeira com forte pre- } \\
\text { sença e liderança empresarial) } \\
\text { que trabalham no sentido de } \\
\text { promover o controle externo das } \\
\text { contas públicas e o combate à } \\
\text { corrupção. }\end{array}$ \\
\hline- & Foro Del Sector Social & $\begin{array}{l}\text { Não tem correspondente direto } \\
\text { no Brasil, pois é uma entidade } \\
\text { que aglutina um conjunto de or- } \\
\text { ganizações do terceiro setor em } \\
\text { prol da promoção do conceito } \\
\text { de RSE. Tem algumas afinida- } \\
\text { des com o GAO, que também } \\
\text { propõe esse tipo de ação, mas } \\
\text { com foco na norma ISO } 26.000 \text { e } \\
\text { com algumas ações pontuais da } \\
\text { Abong. }\end{array}$ \\
\hline- & $\begin{array}{l}\text { larse (Instituto Argentino } \\
\text { de Responsabilidad Social } \\
\text { Empresaria) }\end{array}$ & $\begin{array}{l}\text { Não tem correspondente direto } \\
\text { no Brasil pois é uma entidade } \\
\text { organizada por não-empresários } \\
\text { (ex-gerentes de fundações de } \\
\text { empresas), mas que produz ma- } \\
\text { terial similar ao do Ethos, guar- } \\
\text { dando com ele correspondência } \\
\text { indireta (afinidade de pensamen- } \\
\text { to). Luis Ulla, diretor executivo } \\
\text { da entidade, é membro do Con- } \\
\text { selho Internacional do Ethos. }\end{array}$ \\
\hline
\end{tabular}




\begin{tabular}{|l|l|l|}
\hline--- & Foro Ecuménico & $\begin{array}{l}\text { Não tem correspondente direto } \\
\text { no Brasil, pois é uma entidade } \\
\text { organizada por um jornalista } \\
\text { (promotor do evento Desafio } \\
\text { Empresario, financiado pelo } \\
\text { Banco Francés) que congrega } \\
\text { um conjunto de instituições reli- } \\
\text { giosas de distintas confissões, já } \\
\text { que as religiões têm afinidades } \\
\text { históricas com o trato da questão } \\
\text { social. Discute sobre RSE rela- } \\
\text { cionando-a com o tema da ética. }\end{array}$ \\
\hline-- & $\begin{array}{l}\text { Não tem correspondente direto } \\
\text { no Brasil, pois é uma associação } \\
\text { judaica que recentemente lançou } \\
\text { o Programa Valor para incentivar } \\
\text { medidas de RSE, sobretudo em } \\
\text { pequenas e médias empresas } \\
\text { e cadeia de valor das grandes } \\
\text { empresas. }\end{array}$ \\
\hline
\end{tabular}

Fonte: Oliveira (2010).

Quais são as diferenças mais notáveis entre os casos observando-se o quadro 1? No caso da Argentina, há uma grande quantidade de organizações da sociedade civil que trabalham com a divulgação do tema e a sua força (presença no espaço público, capacidade de mobilização e liderança) é, olhando-se para o contexto interno, maior que a das entidades de origem empresarial e muito menor na comparação com o Brasil. Inicialmente, especialmente após a crise econômica argentina de 2001, quando o tema ganha de fato importância, a tônica dos discursos das ONGs era a do controle externo das empresas, algo que era formulado assim: "as empresas estão muito poderosas no cenário da globalização; é preciso que a sociedade civil controle as empresas e direcione os investimentos sociais". Esse papel que foi amplamente enfatizado pelo Foro del Sector Social. Os grupos organizados da sociedade civil reclamavam com isso o papel de protagonistas no campo da questão social, justificado pelo know-how e pelo conhecimento de causa adquiridos com a experiência e também pela legitimidade, já que as organizações da sociedade civil inspiram alto grau de confiança, enquanto empresas/empresários, ao contrário, têm baixo grau de confiança na sociedade argentina. Atualmente essa postura parece estar mudando pelo reconhecimento, ao menos normativo, da necessidade de ações parceiras com as empresas ante a envergadura dos problemas sociais a serem enfrentados - a chamada nova pobreza argentina -, embora as empresas sejam ainda vistas com muita desconfiança.

A coleta de dados realizada em dois jornais de cada país, também nos dá uma visão de como o tema da RSE vem sendo incorporado ao debate público de acordo com os quadros 2 e 3. 
Quadro 2 - Total de registros recuperados sobre entidades nos jornais La Nación e Clarín (indicador de visibilidade midiática)

\begin{tabular}{|l|c|c|}
\hline \multicolumn{1}{|c|}{ Entidade } & La Nación & Clarín \\
\hline larse & 39 & 3 \\
\hline GDFE & 2 & 0 \\
\hline Cac & 2 & 0 \\
\hline Ceads & 6 & 0 \\
\hline Aacrea & 34 & 14 \\
\hline El Otro & 21 & 9 \\
\hline Foro Ecuménico & 26 & 16 \\
\hline Amia & 27 & 2 \\
\hline Foro del Sector Social & 35 & 10 \\
\hline Poder Ciudadano & 16 & 3 \\
\hline Idea & 9 & 2 \\
\hline ACDE & 17 & 7 \\
\hline Valos & 9 & 0 \\
\hline
\end{tabular}

Fonte: Oliveira (2010).

O breve retrato do debate público da RSE nos meios impressos de comunicação na Argentina, complementado pelos demais dados coletados na pesquisa, nos mostra os seguintes aspectos: 1) Há uma grande fragmentação e nenhuma liderança; 2) Os empresários locais e os líderes empresariais que atuam nas grandes empresas têm uma preocupação voltada para dentro do próprio negócio, mas não assumem ou sequer cogitam tomar liderança de um movimento mais amplo de aproximação entre estado e sociedade; 3) A grande quantidade de entidades que atuam é inversamente proporcional à força que o tema adquire como movimento, ou seja, muito pequena.

No caso do Brasil, observa-se, de acordo com o quadro 3, uma maior presença do tema no debate público como também uma maior concentração em entidades empresariais (exceção é o Ibase), além de uma liderança do Instituto Ethos e da marcante presença de entidades empresariais tradicionais como a Fiesp.

Quadro 3 - Total de registros recuperados das entidades nos jornais Folha de S.Paulo e O Globo (indicador devisibilidade midiática)

\begin{tabular}{|l|c|c|}
\hline Entidade & Folha de S.Paulo & O Globo \\
\hline Instituto Ethos & 193 & 51 \\
\hline Fiesp & 68 & 6 \\
\hline Gife & 25 & 7 \\
\hline Ibase & 14 & 16 \\
\hline CEBDS & 4 & 1 \\
\hline
\end{tabular}




\begin{tabular}{|l|l|l|}
\hline ADCE & 0 & 0 \\
\hline Amcham São Paulo & 2 & 1 \\
\hline Transparência Brasil & 8 & 3 \\
\hline
\end{tabular}

Fonte: Oliveira (2010).

Observando os quadros acima, nossa hipótese é a de que a dimensão política, constitutiva do tema da RSE no Brasil, está ausente no caso argentino, nem havendo neste último uma liderança assumida por nenhum dos atores que jogam no campo. Afora essa dimensão, todas as demais dimensões - práticas gerenciais de RSE com diferentes finalidades e encaradas com distintos graus de profundidade, métricas, prêmios - circulam pelo campo igualmente ao que assistimos no caso do Brasil.

\section{A RSE E SEUS ANTECEDENTES NO BRASIL E NA ARGENTINA: PERSPECTIVA HISTÓRICA}

De acordo com pesquisas realizadas no contexto latino-americano (RP, 2004; RI, 2005; FE, 2009), o Brasil e o México são os países onde o tema da RSE tem maior enraizamento nas culturas organizacionais das empresas, além de maior visibilidade pública. AArgentina, por seu turno, encontra-se, digamos, numa fase intermediária: o tema é objeto de discussão e de inúmeras práticas nas empresas, embora tenha ainda pouca capilaridade como objeto de debate público. Aqui se apresentam os resultados de uma análise histórica comparativa que pretende ajudar a preencher uma lacuna na literatura. Quase não existem estudos comparativos na América Latina sobre o tema da RSE.

Como anotou José A. Puppim de Oliveira (2006), existe uma vasta produção acadêmica sobre a chamada cidadania corporativa, porém essa produção está voltada para uma discussão da dinâmica interna de cada um dos países latino-americanos e não para uma comparação entre eles. O ponto que buscamos elucidar é por que o movimento da RSE é empresarial no Brasil, enquanto na Argentina está ligado à sociedade civil organizada. Para tanto, nos debruçaremos sobre a história desses países, sobretudo no que diz respeito às relações entre o empresariado e a questão social no quadro mais amplo das relações entre estado, mercado e sociedade. A questão social, entendida como uma contradição em torno da qual "uma sociedade experimenta o enigma de sua coesão e tenta afastar o risco de sua fratura" (Castel, apud Cardoso Jr. e Jaccoud, 2005, p. 184), varia historicamente e por isso a perspectiva de longa duração é de extrema importância para o seu entendimento.

Um estudo dessa natureza deve levar em conta a diferença entre culturas empresariais, a qual se relaciona às distintas trajetórias econômicas, sociais e políticas do Brasil e da Argentina. É evidente que, ao lado das diferenças, há semelhanças, que, tratando-se da dimensão cultural, 
têm a ver com a origem ibérica de nossos costumes e instituições. A presença dominante da Igreja Católica ao longo de vários séculos constitui, talvez, a expressão principal dessa origem ibérica, ao menos no que se refere às concepções e modalidades de ação social de cunho filantrópico. Durante a época colonial, por exemplo, iniciativas de assistência social emanaram, em ambos os países, quase exclusivamente da área religiosa.

Na Argentina, enquanto o estado colonial cuidava das questões sanitárias, a Igreja Católica, especialmente por meio do clero regular, realizava a chamada assistência social caritativa. Mas, além desse trabalho, existiam instituições que, embora sob a sombra da lgreja, tinham aspectos mais independentes e incluíam a participação de leigos. Tais instituições mantinham hospitais, casas para órfãos e mulheres carentes. Além da assistência social, cuidava-se também da educação (Pasanante, 1987; Thompson, 1995; Campetella e Bombal, 2000a, 2000b). Algo semelhante ocorreu no Brasil, onde as santas casas começaram a atuar muito cedo, representando uma antiga modalidade de assistência originária de Portugal. Surgiram também irmandades, confrarias de leigos que cumpriam papéis ao mesmo tempo rituais e assistenciais (Quiroga, 2005).

A partir da independência (no início do século XIX), houve na Argentina uma transferência progressiva e cheia de altos e baixos das obras de caridade em poder de religiosos à responsabilidade de organizações laicas e com um maior controle do estado. Daí até o início do século XX foi um período de grande prosperidade no que se refere à constituição de entidades privadas de assistência. Nesse sentido, o exemplo mais notável é o da Sociedade de Beneficência (SB), fundada em 1823, responsável pelas principais tarefas de filantropia e assistência social no país até meados do século $X X$, de forma privada, porém, em grande parte, com fundos públicos. Era uma entidade que reunia a elite econômica da agroexportação e as grandes famílias da política e da alta administração. Na prática, entretanto, essa passagem significou mais uma troca de administração mantendo-se em essência os mesmos valores e instrumentos de solidariedade social.

Paralelamente, uma ampla rede de solidariedade social no âmbito da sociedade civil se formou com as sociedades de socorros mútuos, as cooperativas, as associações de bairro, as bibliotecas e os clubes privados, bem como as associações de imigrantes. Os confrontos entre capital e trabalho, face mais visível da questão social nas sociedades modernas, foram bastante fortes na Argentina, especialmente no início do século XX e na década de 1910. Mas foram contornados do ponto de vista político com o sufrágio universal da Lei Saenz-Peña de 1912 e algumas garantias trabalhistas como as primeiras caixas de aposentadoria (L. Romero, 2001; J. L. Romero, 2004).

No período agroexportador (1880-1930), permaneceu na Argentina um projeto de nação fundado na dicotomia civilização versus barbárie, do qual a expressão maior é o pensamento da geração de $1880^{3}$ (Fausto; Devoto, 2004). Fernando Henrique Cardoso (1971) enxerga nesse período a capacidade da elite proprietária de estabelecer um domínio solidamente baseado numa economia exportadora em expansão, como também em um projeto de desenvolvimento aceito 
por todos e racionalizado pela ideologia liberal, calcado no livre jogo do mercado e justificado por representar os interesses de uma maioria de consumidores e não de uma minoria de produtores, domínio que não enfrentou nenhum tipo de contestação. As contestações, advindas da pressão popular, dirigiam-se à abertura do sistema político e à melhor distribuição da renda, tendo sido ao menos parcialmente atendidas. Na Argentina, a participação popular tem um caráter simbólico de peso expressivo. De acordo com Glik (s. d, p. 10), "nos livros didáticos, a figura do cabildo abierto e a frase 'O povo quer saber de que se trata' transferem a imagem de uma primeira participação popular nos assuntos de governo". A participação popular sob convocatória das elites, por exemplo, nas passeatas e nos protestos de rua revela, por um lado, um viés da dominação, mas, por outro, a importância simbólica dos trabalhadores como partícipes das reivindicações. No Brasil, a evolução foi diferente. Não surgiu nenhum órgão filantrópico tão poderoso e abrangente quanto a Sociedade de Beneficência. O engajamento de elites econômicas e de empresas em ações sociais não-lucrativas sempre acompanhou a trajetória do capitalismo brasileiro, mas como um fenômeno secundário marcado pelas motivações de caráter pessoal (consciência religiosa e/ou filosófica) quase insignificantes frente aos fortes níveis de desigualdade social. As ações não-econômicas desses agentes econômicos, historicamente, sempre foram importantes para demarcar suas fronteiras de classe, tanto no sentido do autorreconhecimento quanto na determinação de limites em relação a outras classes sociais.

Isso é um ponto comum com a Argentina. Contudo, uma diferenciação que se mostra importante para o nosso ponto é a visão das elites sobre os grupos organizados da sociedade civil e sobre a população de um modo geral. No Brasil, as elites políticas e empresariais, tenderam historicamente a conceber a sociedade civil como frágil (o pobre é despreparado para a participação) e os movimentos de protesto ou de insatisfação social para com os dirigentes - quando visíveis no espaço público - eram tratados como "bagunça", desordem (Carvalho, 1998; Valladares, 1991), inclusive nos conflitos entre capital e trabalho, que foram fortemente reprimidos pelo estado. Os movimentos associativos - sociedades de socorros mútuos, cooperativas e outros - que poderiam representar uma rede de solidariedade social paralela ao estado, sempre foram vistos com desconfiança e controlados pela via legal, quando não diretamente combatidos (Viscardi; Jesus, 2007).

De modo sintético, observa-se no período agroexportador brasileiro a presença de uma questão social grave (que incluía a negligência em relação aos negros após a abolição e a falta de regulamentação do mercado de trabalho), movimentos populares fracos ou, melhor dizendo, enfraquecidos pela força repressora do poder estatal oligárquico e pela força política das elites, expressa, por exemplo, por meio de menosprezo aos movimentos e às manifestações populares na imprensa. Observa-se também uma ação social impositiva na dimensão estatal,

\footnotetext{
${ }^{3}$ O ideário da nação da geração de 1880 era inspirado no positivismo e no liberalismo. Pensavam que o estado tinha como objetivo criar um marco jurídico para o bom funcionamento do modelo agroexportador, além de apoiar e estimular as atividades comerciais e financeiras. Foram responsáveis pela criação do exército nacional, do sistema judicial nacional e de uma burocracia dependente do poder executivo.
} 
liberal na dimensão empresarial (a pobreza seria problema do pobre), bem como esparsa e fragmentada na dimensão associativa. Nesse período emerge um projeto de nação fundado na autonomia frente à tutela colonial, não de um povo, mas de uma pequena parte dele, e sustentado simbolicamente na hibridização cultural.

"Conciliação" e "cordialidade" tanto na política partidária como na racial (da qual é expressão o branqueamento como ideologia racial na Primeira República), ao invés das convulsões militares e civis, das rupturas e refundações, da universalização da educação e dos direitos civis presentes na Argentina, se tornaram os elementos fundantes da nação ou, melhor dizendo, dos dois brasis, conforme a formulação de Florestan Fernandes (1975, p. 206) aludindo à coexistência de duas nações: "a que se incorporava à ordem civil (a rala minoria, que realmente constituía uma 'nação de mais iguais', e a que estava dela excluída, de modo parcial ou total (a grande maioria, de quatro quintos ou mais, que constituía a 'nação real'"4.

O Brasil é uma nação (ou, melhor, duas nações no sentido apontado por Fernandes) constituída por um estado forte e uma sociedade civil organizada que compete por espaço com o e no estado. Na Argentina, ao contrário, "o caráter tardio da formação do estado permaneceu solidário de uma grande vitalidade associativa e de uma estruturação particularmente robusta dos grupos dirigentes" (Rouquié, 1985, p. 14). Assim, "de um lado, o padrão argentino se configura por um processo tardio de formação do estado nacional, enquanto que, no caso brasileiro, o estado se constitui precocemente. De outro lado, no plano da dinâmica liberal, o padrão é praticamente inverso: na Argentina, o ritmo de expansão da arena política é mais forte e amplo, no Brasil, ele se desenvolve de forma mais lenta e restrita (Trindade, 1985, p. 51). Enquanto na Argentina os setores mais numerosos da nação se transformaram com os avanços da economia agroexportadora, no Brasil eram setores mais limitados os que se transformavam.

No que tange à disputa por hegemonia entre o setor privado e o estado em relação à questão social, uma fase de especial interesse foi a de meados do século XX.

Na Argentina, passado o longo momento de retrocesso conservador conhecido como "Década infame", a partir de 1930, a ascensão de Juan Domingo Perón em 1943 resultou na incorporação, pelo estado, da política social, sendo delegada aos sindicatos a sua execução. Como expressão da nova correlação entre o estado e o setor empresarial, a Sociedad de Beneficencia foi substituída pela Fundación Eva Perón. A rede de solidariedade social representada pelas sociedades de socorros mútuos foi incorporada às ações estatais em paralelo ao redesenho dos sindicatos por categoria de trabalhadores e com abrangência nacional. Assim, o peronismo desenvolveu um sistema nacional de segurança social massivo que cobriu praticamente todos os trabalhadores, além de tê-la assumido como um mecanismo de redistribuição econômica que o estado tem tanto a necessidade quanto a obrigação de proporcionar. 
Vale dizer que até a emergência de Perón e do nacional-populismo na Argentina os interesses da oligarquia rural prevaleciam sobre os interesses industriais. Mas se os últimos passam a valer não foi por pressão política dos empresários industriais, mas sim como um projeto de estado. Os industriais, por sua vez, não desafiaram inicialmente a Perón, mas em pouco tempo a força política dele os coloca sem reconhecimento como interlocutores do estado: a Unión Industrial Argentina (UIA) sofre intervenção estatal, a Confederación Argentina del Comercio, la Industria y la Producción (Cacip) desaparece, enquanto a Sociedad Rural Argentina (SRA) e a Bolsa de Comercio de Buenos Aires (BCBA) se colocam numa posição resignada.

No Brasil, a Revolução de 1930 abriu uma fase de estatização da questão social, que se prolongou com a ditadura varguista do Estado Novo, de 1937 a 1945 . Com o prenúncio da liberalização política, houve forte mobilização do empresariado no sentido de assumir papel estratégico, substituindo o estado na arena social. A criação do Sistema $S^{5}$, destinado à educação para o trabalho e aos serviços sociais de atendimento aos trabalhadores e às suas famílias, era expressão desse esforço. Tal projeto, é claro, correspondia ao desenho corporativo de organização das classes que vigorava no Brasil (como também na Argentina peronista). Aqui não alcançava a maioria da população, atendo-se apenas aos trabalhadores urbanos do mercado formal. Esta terá sido uma das razões pelas quais não logrou êxito o investimento que a elite empresarial fez para assumir maior protagonismo no regime democrático instituído em 1946. Uma hegemonia burguesa só se tornaria viável com a queda do regime populista, em 1964, mas então o empresariado se tornou parceiro dos militares em um regime ditatorial. O que se nota nesse período é que as elites empresariais brasileiras tiveram maior poder de penetração no aparato estatal que as elites empresariais argentinas, sempre mais afastadas dos assuntos públicos, especialmente daqueles que não estivessem relacionados à política econômica (Jáuregui, 2002).

Assim, Brasil e Argentina, em momentos diferentes, tiveram uma legislação trabalhista e sindical para lidar com as desigualdades advindas da industrialização. O estado argentino disputou a hegemonia da questão social com a sociedade civil, enquanto no Brasil a disputa foi mais diretamente negociada com os empresários, inclusive fazendo-lhes algumas concessões em termos de política econômica para que pudessem acatar a legislação (Gomes, 1979).

Na Argentina, o populismo peronista durou até 1955 e deu lugar a fases ditatoriais entremeadas de tentativas malogradas de regimes democráticos. Dentre estes, houve o período do desenvolvimentismo que como ideário econômico propunha a proteção das indústrias nacionais da concorrência de produtos estrangeiros com base na parceria entre capital privado, capital estatal e capital estrangeiro, mas o empresariado argentino se colocou numa posição distante do estado, ao contrário do que ocorreu no Brasil (Sikkink, 1993). Aqui ganhou força nesse momento, entre vários setores das elites, a ideia de que a solução para os problemas sociais (especialmente os conflitos entre capital e trabalho) deviam vir do desenvolvimento econômico pela entrada

${ }^{4}$ Embora a análise de Florestan, nessa citação, esteja circunscrita ao período da Primeira República no Brasil, ele notará uma permanência dessa divisão ao longo da história brasileira no século XX. 
do país numa era de capitalismo avançado e que, portanto, os interesses da indústria eram os interesses da nação.

Já as ditaduras adotaram, por via de regra, políticas econômicas liberal-privatistas que enfraqueceram substancialmente a capacidade estatal de implementar políticas públicas no campo social. Isso, em tese, abria espaço para o empresariado assumir papel mais ativo. Mas só com a abertura política, na década de 1980, é que se abriria nova oportunidade para a disputa por hegemonia em relação à questão social - a qual foi evidenciada, sobretudo, na Constituinte de 1987-1988 no Brasil. O foco na inclusão social, a adoção não tão radical dos preceitos neoliberais e a universalização da proteção aos cidadãos consagrada no texto constitucional de 1988 descortina um novo momento na história do país. É claro que isso não quer dizer que por aqui tenhamos resolvido toda a questão social, mas que alguns passos importantes na direção da seguridade social foram dados concomitantemente com uma rearticulação da sociedade civil e maior participação social na arena pública com maior pluralidade de visões - incluindo-se aqui as dos empresários.

Como não poderia deixar de ser, as transformações sociais e econômicas desse período tiveram desdobramentos específicos na Argentina. A implementação de políticas econômicas liberais possibilitou a entrada maciça de capital estrangeiro e a privatização de empresas e serviços públicos. Com o regime de economia aberta, assiste-se ao desmantelamento progressivo das políticas de proteção social na Argentina, que adotou radicalmente o modelo do estado mínimo. Em contraponto, a sociedade civil, sempre muito ativa, seguiu fazendo seu trabalho com expressivo crescimento do chamado terceiro setor. Mas agora ele é um conta-gotas no mar de uma questão social que só se aprofundou desde os governos militares (1976 a 1984) e que foi especialmente marcada pelo modelo neoliberal dos dois governos de Carlos S. Menem (entre 1989 e 1999) e da forte crise econômica de 2001, cujos efeitos são ainda notáveis. O processo de privatizações permitiu o ingresso de novas empresas internacionais no país e, junto com elas, novas exigências em relação à responsabilidade social empresarial, mas não por acaso quem assumiu a sua promoção na forma de um movimento foram as organizações da sociedade civil.

No Brasil, assistiu-se nesse período a um crescimento do interesse das empresas na realização de projetos de diferentes tipos e em diferentes áreas sociais e ao forte engajamento de empresários na sua promoção. Esse movimento foi impulsionado pela criação do Grupo de Institutos, Fundações e Empresas (Gife) em 1995, do Prêmio de Contribuição Empresarial à Comunidade

\footnotetext{
${ }^{5}$ O Sistema S é um conjunto de organizações criadas e dirigidas por entidades corporativas dos empresários voltadas para o treinamento profissional, assistência social, consultoria, pesquisa e assistência técnica. O Sistema $S$, inicialmente voltado para educação profissional na indústria e no comércio, foi idealizado por líderes empresariais - Euvaldo Lodi, da Confederação Nacional da Indústria, e Roberto Simonsen, da Federação das Indústrias de São Paulo - com o objetivo de fomentar a transformação do Brasil, um país ainda agrário, num país efetivamente industrial. Esses líderes idealizaram um projeto e o apresentaram ao então presidente da República, Getúlio Vargas, com base num mecanismo de "autotributação", ou seja, um sistema de contribuições compulsórias incidentes nas folhas de pagamento dos trabalhadores pelas empresas financiaria programas educacionais altamente comprometidos com a meta de industrialização do país, sob a liderança administrativa e estratégica dos empresários.
} 
(Eco), da Câmara Americana de Comércio de São Paulo, e, muito especialmente, do Instituto Ethos de Empresas e Responsabilidade Social, em 1998. Os projetos e as práticas das empresas no campo social se diversificavam bastante, espalhando-se pelas diversas regiões do país. No início da década, o Instituto de Pesquisa Econômica Aplicada (Ipea) registrou esse processo de expansão em vários estudos empíricos (Peliano, 2000, 2001a, 2001b, 2001c; Ipea, 2005, 2006).

No início do século XX, a Argentina possuía uma das economias mais dinâmicas do mundo, enquanto o Brasil vivia uma difícil transição da escravidão para o regime de trabalho livre. Cem anos depois, o Brasil se tornou uma economia industrializada e bem diversificada, ao passo que o país vizinho não logrou avançar de forma sustentável após o esgotamento do antigo sistema agroexportador que lhe proporcionara tanta riqueza no passado. As burguesias dos dois países refletem esses padrões contrastantes de desenvolvimento, o que se evidencia nos seus movimentos de divulgação de discursos e práticas de RSE.

Com tais traços históricos, é possível responder ao ponto que nos colocamos como pergunta ao início do trabalho. A não-mobilização do empresariado argentino em relação à liderança da promoção e das práticas de RSE parece ter a ver com uma tradição histórica de afastamento do jogo político, sobretudo nas matérias que ultrapassam o âmbito das decisões econômicas. Por outro lado, o protagonismo da sociedade civil no que se refere à questão social empresta-lhe a legitimidade necessária para assumir tal liderança. No Brasil, a situação é inversa.

\section{CONSIDERAÇÕES FINAIS}

O que a perspectiva histórica e o material empírico nos sugeriram é que o social é objeto de disputas de ambas as elites econômicas - a brasileira e a argentina. Porém, no caso brasileiro há uma atuação direta dos empresários nas estruturas estatais, por meio de cargos eletivos e de importantes redes de lobby e de relacionamento com a burocracia: os empresários querem ser o estado, ou seja, ocupar a posição de controle e hegemonia no espaço público. No caso argentino, por sua vez, a atuação é indireta e os empresários utilizam a mediação das organizações da sociedade civil para fazerem valer seus interesses e objetivos de controle e hegemonia no espaço público: as organizações da sociedade civil é que querem ser o estado.

Tais características tiveram implicações na maneira como a mobilização pela RSE ocorreu nos dois casos em foco. No Brasil, a liderança é empresarial, enquanto na Argentina ela é da sociedade civil. Essa diferença se explica a partir do processo histórico que revela uma maior aproximação do empresariado brasileiro às coisas públicas - ainda que por vias não convencionais como a político-partidária - que a do empresariado argentino, mais resignado à esfera dos negócios acomodando-se aos sucessivos governos. Já a sociedade civil argentina, muito mais articulada e ativa no espaço público que a brasileira, supõe-se "dona" da questão social, 
cabendo a ela liderar o processo de intervenção social das empresas até porque "resisten a un archivo" e, com isso, contam com a credibilidade da sociedade. Há que se ressaltar ainda que a liderança brasileira é marcada pela presença do Instituto Ethos no campo, referência não só para o Brasil, mas para a Argentina (e outros países). O Ethos é uma entidade empresarial não de molde corporativista, mas atuante como grupo organizado da sociedade civil.

O discurso da RSE nos seus termos cá e lá é o mesmo. Aparentemente, pasteurizado nos parâmetros da globalização e integrado à chamada cultura de negócios (Barbosa, 2002). Numa tentativa de organização mais generalizante dos dados, ensaiamos a seguinte distinção. No Brasil, o discurso da RSE é empresarial e poderia ser reduzido desta forma: dado o cenário de globalização e liberalização econômica e, consequentemente, restrição do tamanho e da ação do estado, as empresas são poderosos agentes e é legítima sua intervenção no campo social. Nesse sentido, a boa conduta social das empresas faz bem a todos, inclusive aos negócios, principalmente num contexto social em que o estado tem sua capacidade de investimentos limitada e que a sociedade, vulnerável e frágil, necessita de amparo. Na Argentina, o discurso da RSE é da sociedade civil organizada e pode ser reduzido da seguinte forma: dado o cenário de globalização, liberalização econômica e, consequentemente, restrição do tamanho e da ação do estado, os empresários se veem com seus poderes de intervenção no espaço público ampliados, cabendo à sociedade civil o dever de zelar para que atendam de fato à promoção da cidadania. Os empresários e as empresas tidos como manipuladores da sociedade, por um lado, e o estado visto como falido e corrupto, por outro, precisam ser controlados pelos grupos organizados da sociedade civil.

São duas visões que espelham os contextos históricos particulares dos quais emergiu a noção de RSE nos países aqui examinados. O contraste dos discursos nos dois países pode contribuir para a análise política da questão, uma vez que implica disputas diversamente organizadas do ponto de vista do seu conteúdo porém estruturalmente parecidas (envolvem os mesmos atores, os mesmos termos, as mesmas posições). Estudos comparativos que levem em consideração a avaliação histórica do enraizamento da RSE - como discutimos - em outras realidades poderão enriquecer nosso conhecimento do tema, ampliando a capacidade de descrevê-lo e analisá-lo adequadamente.

\section{REFERÊNCIAS}

AGÜERO, Felipe. Business social responsibility in Latin America: Argentina, Brazil, Chile, Colômbia, México and Peru. (Report for Ford Foundation). Miami: School of International Studies / University of Miami, 2002.

BARBOSA, Lívia. Globalização e cultura de negócios. In: KIRCHNER, Ana Maria; GOMES, Eduardo R.; CAPPELLIN, Paola (Org.). Empresa, empresários e globalização. Rio de Janeiro: Relume-Dumará / Faperj, 2002.

CAMPETELLA, Andrea; BOMBAL, Inés González. Historia del sector sin fines de lucro en Argentina. In: ROITTER, Mario; BOMBAL, Inés Gonzalez (Org.). Estudios sobre el sector sin fines de lucro en Argentina. Buenos Aires: CNPJHU-Cedes, 2000a. 
El desarrollo histórico del sector sin fines de lucro en Argentina: debate con algunos modelos teóricos. In: ROITTER, Mario; BOMBAL, Inés Gonzalez (Org.). Estudios sobre el sector sin fines de lucro en Argentina. Buenos Aires: CNPJHU-Cedes, 2000b.

CARDOSO, Fernando Henrique. Ideologías de la burguesía industrial en sociedades dependientes (Argentina y Brasil). México: Siglo XXI Editores, 1971.

CARDOSO JR., José Celso; JACCOUD, Luciana. Políticas sociais no Brasil: organização, abrangência e tensões da ação estatal. In: JACCOUD, Luciana (Org.). Questão social e políticas sociais no Brasil contemporâneo. Brasília: Ipea, 2005.

CARVALHO, José Murilo. Os bestializados: o Rio de Janeiro e a república que não foi. 3. ed. São Paulo: Companhia da Letras, 1998.

DULCI, Otávio. Política e recuperação econômica em Minas Gerais. Belo Horizonte: Editora da UFMG, 1999.

FAUSTO, Boris; DEVOTO, Fernando. Brasil e Argentina: um ensaio de história comparada (1850-2002). São Paulo: Editora 34, 2004.

FE - FORUM EMPRESA. Estado de la responsabilidad social empresarial en América Latina bajo la mirada de ejecutivos de empresas - 2009. Chile, 2009. Disponível em: <http://www.centroscomunitariosdeaprendizaje.org.mx/sites/ default/ files/El_estado_de_la_RSE_bajo.pdf>.

FERNANDES, Florestan. A revolução burguesa no Brasil: ensaio de interpretação sociológica. Rio de Janeiro: Zahar Editores, 1975.

GLIK, Mônica Sol. Ordem e progresso, civilização e barbárie. Perón, Vargas e positivismo. (Argentina-Brasil, 1930-1955). Monografia (História Contemporânea) - Universidad Autónoma de Madrid, s/d.

GOMES, Ângela Maria de Castro. Burguesia e trabalho: política e legislação social no Brasil, 1917-1937. Rio de Janeiro: Campus, 1979.

HORA, Roy. Empresarios y politica en la Argentina, 1880-1916. In: CONGRESS OF THE INTERNATIONAL ECONOMY HISTORY ASSOCIATION, XIII, Buenos Aires, jul. 2001. Trabalho apresentado no Simposio 46 - Business organizations and political economy of the XXth century Latin America. Anais..., Buenos Aires, Argentina / Utrecht, Holanda, 22-26 de julho de 2002.

IPEA - INSTITUTO DE PESQUISAS ECONÔMICAS APLICADAS. A iniciativa privada e o espírito público: a evolução da ação social das empresas nas regiões Sudeste e Nordeste. Brasília, Rede Ipea de Pesquisa / BID / Escritório da Cepalno Brasil, jun. 2005. Disponível em: <http://www.ipea.gov.br/ acaosocial//MG/pdf/doc-23.pdf Acesso em 16/01/2008>.

A iniciativa privada e o espírito público: a evolução da ação social das empresas no Brasil. Brasília, Rede Ipea de Pesquisa / BID / Escritório da CepalL no Brasil, jul. 2006. Disponível em: <http://www.ipea.gov.br/ acaosocial//MG/pdf/ doc-28.pdf>. Acesso em: 16/01/2008.

JÁUREGUI, Aníbal Pablo. Élites empresarias y políticas de desarrollo: Brasil y Argentina - 1920-1955. Tese (Doutorado em História) - Universidad Nacional del Centro de la Provincia de Buenos Aires, Tandil, 2002.

OLIVEIRA, José Antônio Puppim de. Introduction. In: Corporate citizenship in Latin America: new challenges for business. Journal of Corporate Citizenship, n. 21, 2006. Disponível em: <http://www.greenleaf-publishing.com/content/ pdfs/jcc21intr.pdf>.

OLIVEIRA, Luciana de. Ideias do presente, práticas do passado? Elites empresariais e a questão social no Brasil e na Argentina. Estudo comparativo de discursos e práticas de responsabilidade social empresarial. 2010. 440f. Tese (Doutorado em Ciências Humanas: Sociologia e Política) - Universidade Federal de Minas Gerais, Belo Horizonte. 
PASSANANTE, María Inés. Pobreza y acción social en la historia argentina: de la beneficencia a la seguridad social. Buenos Aires: Editorial Humanitas, 1987.

PELIANO, Anna Maria T. Medeiros (Coord.). A iniciativa privada e o espírito público: um retrato da ação social das empresas do Sudeste brasileiro. Brasília: Ipea, 2000.

. Bondade ou interesse? Como e por que as empresas atuam na área social. Brasília: Ipea, 2001a. Ipea, 2001b.

A iniciativa privada e o espírito público: um retrato da ação social das empresas do Nordeste brasileiro. Brasília: A iniciativa privada e o espírito público: um retrato da ação social das empresas do Sul do Brasil. Brasília: Ipea, 2001c.

QUIROGA, Ana Maria. Assistência e poder. Revista Praia Vermelha: Estudos de Política e Teoria Social, Escola de Serviço Social da Universidade Federal do Rio de Janeiro, n. 18, 1. sem. 2008.

RI - RED INTERAMERICANA DE RSE. Situación de la RSE en Latinoamérica hacia un desarrollo sustentable. Valparaíso, Chile: Red Interamericana de RSE / PUC Valparaíso, set. 2005. Disponível em: <http://www.vincular.cl/ publicaciones/ SituacionRSELatinoamerica.pdf>.

RP - RED PUENTES. Visión y propuestas de Red Puentes sobre la tarea de la responsabilidad social empresarial en América Latina. [S. I.]: Red Puentes, 2004. Disponível em: <http://lasociedadcivil.org/docs/ciberteca/ posicionamiento_cvico_rp_marzo_2005.pdf>.

ROMERO, José Luis. Breve historia de la Argentina. 5. ed. Buenos Aires: Fondo de Cultura Econômica, 2004.

ROMERO, Luis Alberto. Breve historia contemporánea de la Argentina. 2. ed. Buenos Aires: Fondo de Cultura Econômica, 2001.

ROUQUIÉ, Alain. Introdução geral: querer a democracia. In: ROUQUIÉ, Alain; LAMOUNIER, Bolívera; SHVARZER, Jorge (Org.). Como renascem as democracias. São Paulo: Editora Brasiliense, 1985.

SIKKINK, Kathryn. Las capacidades y la autonomía del estado en Brasil y la Argentina: un enfoque neoinstitucionalista. Desarrollo Económico, v. 32, n. 128, enero-marzo 1993. Disponível em: <http://escueladegobierno.chaco.gov.ar/ files/ Sikkink.pdf>.

THOMPSON, Andrés. Beneficencia, filantropía y justicia social: el tercer sector en la historia argentina. In: THOMPSON, Andrés (Org.). Público y privado: las organizaciones sin fines de lucro en Argentina. Buenos. Aires: Losada / Unicef, 1995.

TRINDADE, Hélio. Bases da democracia brasileira: lógica liberal e práxis autoritária. In: ROUQUIÉ, Alain; LAMOUNIER, Bolívar; SHVARZER, Jorge (Org.). Como renascem as democracias. São Paulo: Editora Brasiliense, 1985.

VALLADARES, Lícia. Cem anos pensando a pobreza (urbana) no Brasil. In: BOSCHI, Renato (Org.). Corporativismo e desigualdade: a construção do espaço público no Brasil. Rio de Janeiro: Rio Fundo Editora / luperj, 1991.

VISCARDI, Cláudia Maria Ribeiro; JESUS, Ronaldo Pereira de. A experiência mutualista e a formação da classe trabalhadora no Brasil. In: FERREIRA, Jorge; REIS, Daniel Aarão. A formação das tradições (1889-1945). Rio de Janeiro: Civilização Brasileira, 2007

Recebido em: 02.08.2012 / Aceito em: 22.03.2013 


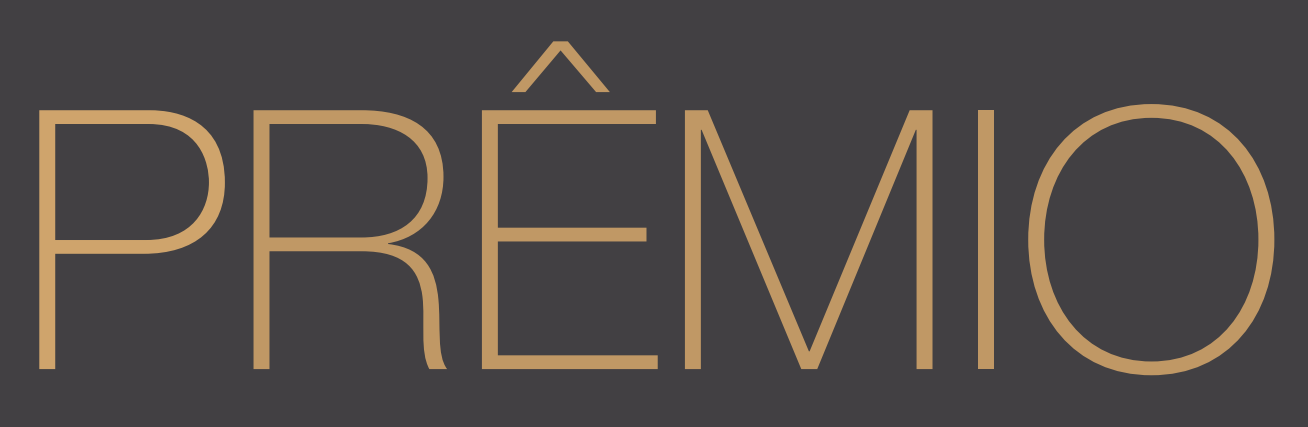

O

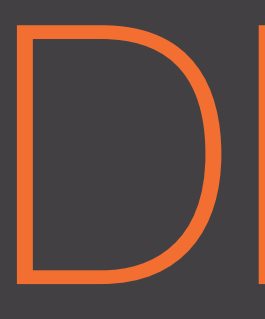
EB

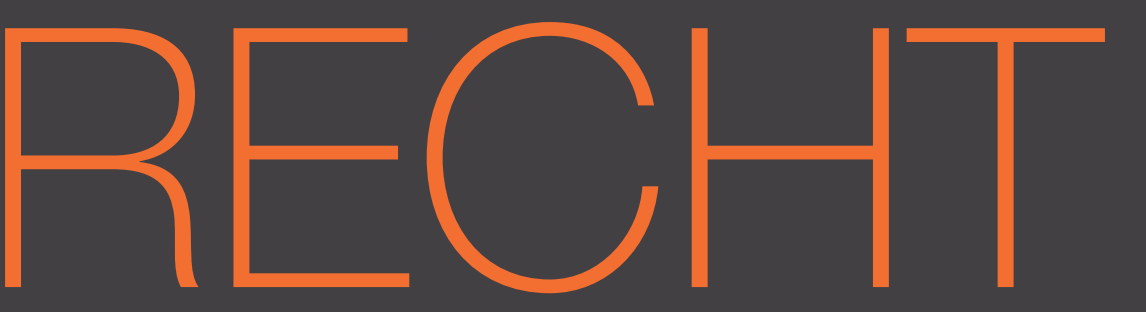

$\square$
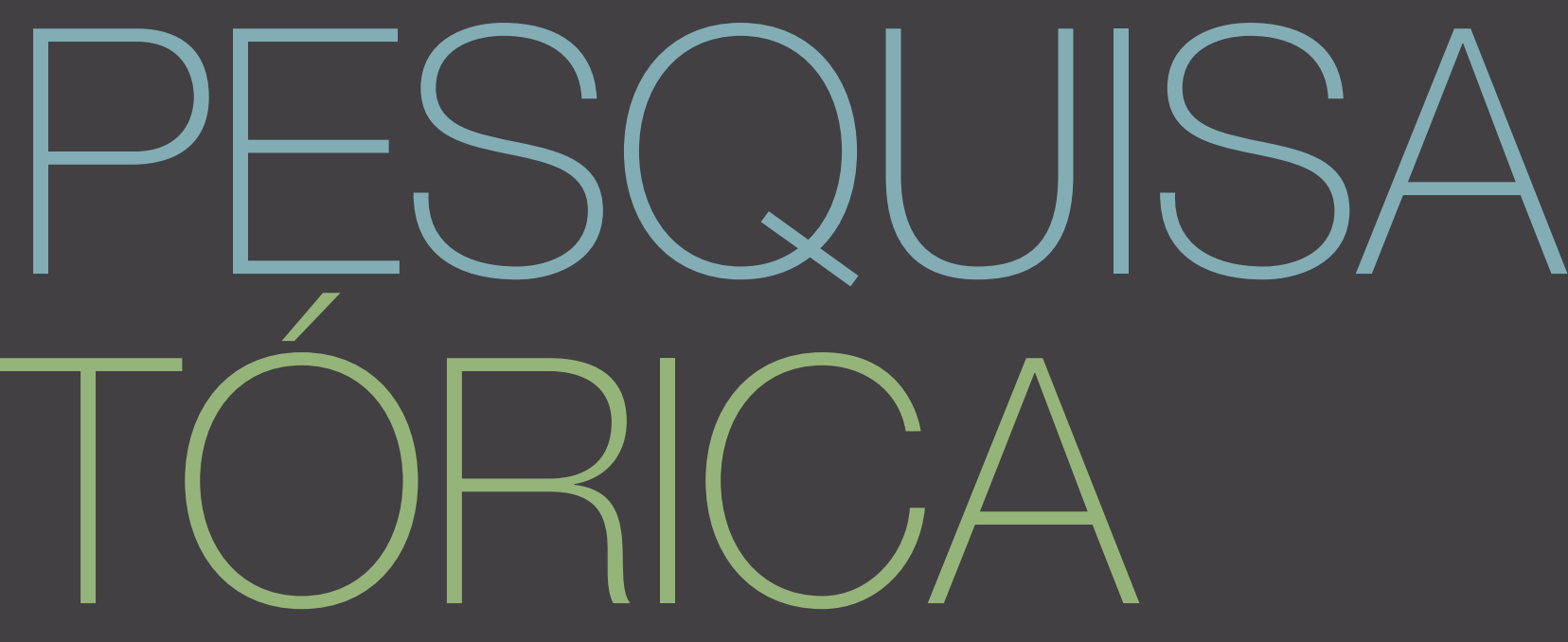

HISTORICA

CLARIVAL DO PRADO VALLADARES
CLARIVAL DO PRADO VALLADARES
HÁ 10 ANOS ESTIMULANDO A DESCOBERTA E A PRESERVAÇÃO DA MEMÓRIA BRASILEIRA

Desde 2003 o Prêmio Odebrecht de Pesquisa Histórica vem apoiando o trabalho de pesquisadores que se dedicam a temas inéditos da História do Brasil.

A cada ano, um projeto de pesquisa é financiado, e seu resultado é colocado à disposição do público em um livro de arte cuidadosamente editado e ricamente ilustrado.

Dessa forma, a Organização Odebrecht ajuda a valorizar o patrimônio cultural brasileiro e a preservar a nossa memória para as futuras gerações.

If/premioodebrechthistoria | www.odebrecht.com/pesquisahistorica
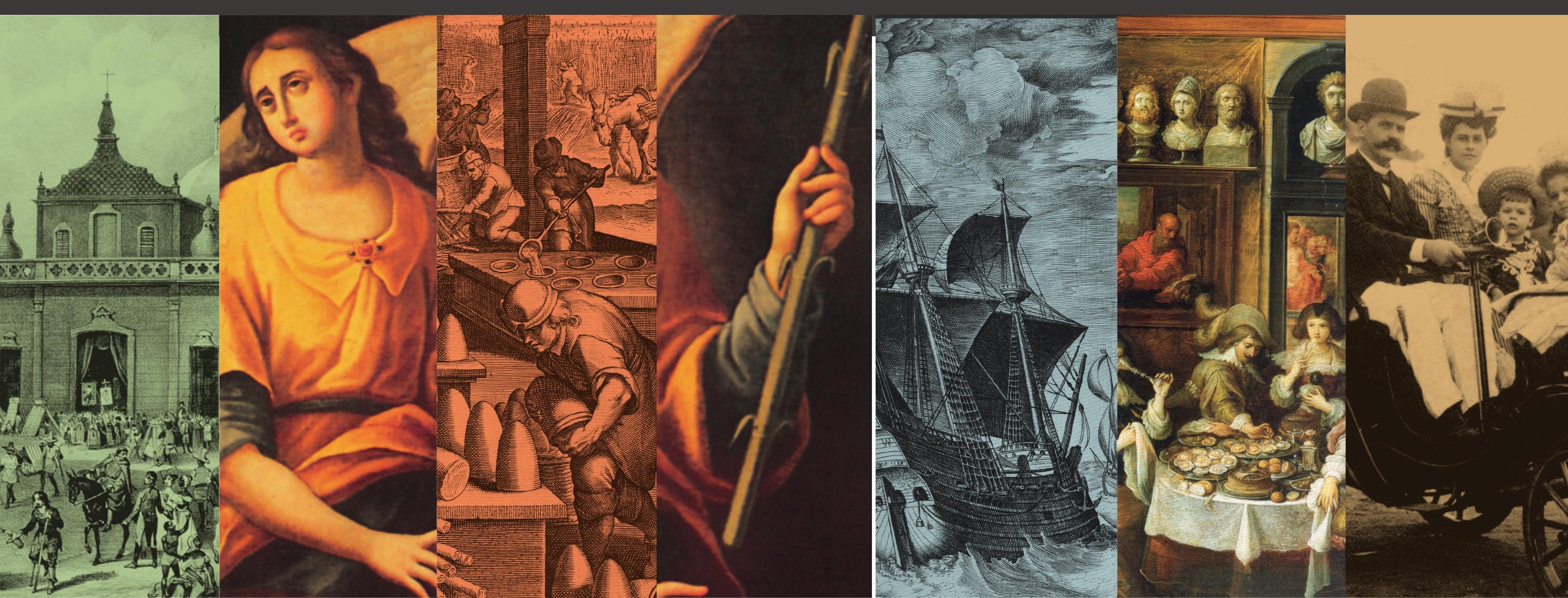

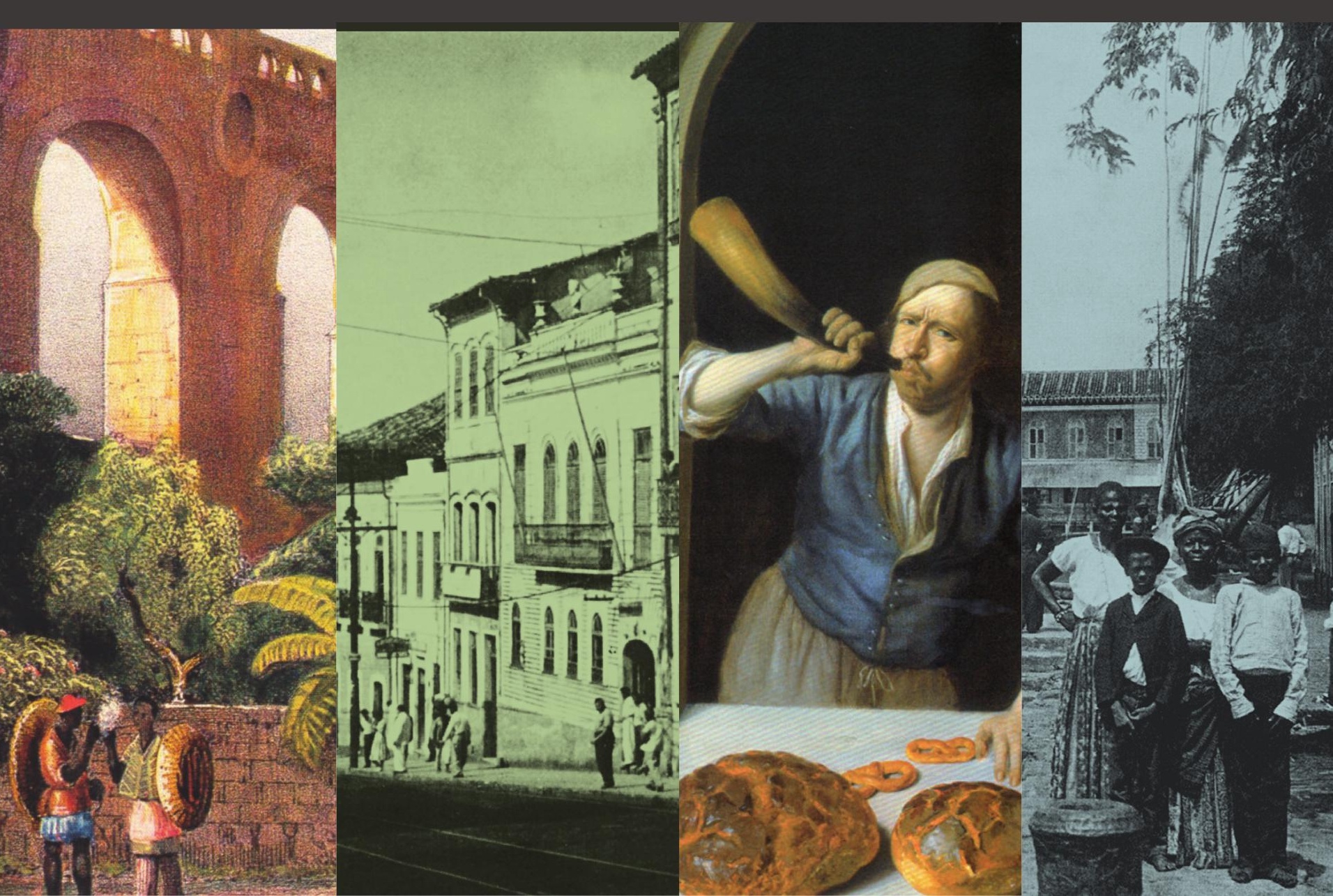

